\title{
Economic Assessment of Producing Corn and Cellulosic Ethanol Mandate on Agricultural Producers and Consumers in the United States
}

\author{
Naveen C. Adusumilli, ${ }^{1}$ Ronald D. Lacewell, ${ }^{2}$ C. Robert Taylor, ${ }^{3}$ and M. Edward Rister ${ }^{4}$ \\ ${ }^{1}$ Department of Ag Economics and Agribusiness, Louisiana State University Agricultural Center, \\ Red River Research Station, 262 Research Station Drive, Bossier City, LA 71112, USA \\ ${ }^{2}$ Texas A\&M AgriLife, Office of Federal Relations, Suite 150, 1500 Research Parkway, College Station, TX 77843-2259, USA \\ ${ }^{3}$ College of Agriculture, Auburn University, Auburn, AL 36849-5406, USA \\ ${ }^{4}$ Department of Agricultural Economics, 600 Kimbrough Boulevard, Suite 211B, TAMU 2124, College Station, TX 77843-2124, USA
}

Correspondence should be addressed to Naveen C. Adusumilli; nadusumilli@agcenter.lsu.edu

Received 20 November 2015; Accepted 7 February 2016

Academic Editor: Jean Paul Chavas

Copyright (C) 2016 Naveen C. Adusumilli et al. This is an open access article distributed under the Creative Commons Attribution License, which permits unrestricted use, distribution, and reproduction in any medium, provided the original work is properly cited.

\begin{abstract}
Strong support for the biofuels program in the USA is expected to influence dedicated biomass crops production. Their production is expected to compete for resources with traditional crops and in turn influence commodity prices, economic surplus, and trade balance. Implications of dedicated biomass crop as bioenergy feedstock, alternative energy policies, and government initiatives on agricultural producers and consumers are evaluated using a national quantitative model, AGSIM. Economic impacts include effect on cropping patterns, crop prices, fertilizer prices, consumer and producer surplus, and trade balance. Economic analyses based on alternative assumptions related to marginal lands currently in conservation use returning to crop production as well as biomass crop yields are conducted. Results indicate that present biofuel policies are associated with large costs to consumers in terms of increased commodity prices and negative trade balance. Increase in net farm income is offset by decrease in consumer surplus. The results represent a robust set of economic impacts, which suggests policy makers to consider the unexpected economic consequences of bioenergy policy and warrants consideration of multiple alternative energy sources to achieve a sustainable energy goal.
\end{abstract}

\section{Introduction}

Wide ranges of energy sources are being considered, such as ethanol derived from grains, cellulosic plant materials, and dedicated biomass energy crops to meet the growing energy demand. While the production of biofuels may be politically, and at first thought, economically attractive, several potential issues could prove costly in terms of land use, water use and quality, energy balance, food and animal feed availability, commodity prices, government outlays, and trade balance. With more than 80 percent of the world's food supply comprised of grains, competition between food and fuel crops for land and other resources is expected to translate into higher prices for staple foods globally $[1,2]$. Similar relationships were found to exist in the evaluation of the impacts of the production of grain ethanol mandates $[3,4]$.
The US Renewable Fuel Standard (RFS) proposed to address the growing energy needs of the country and reduce reliance on imported oil mandates production increases over recent levels for 2015 and 2016. The proposed volumes of cellulosic biofuels increased from 33 million gallons in 2014 to 106 and 206 million gallons for 2015 and 2016, respectively [5]. It is predicted that US biofuels production by 2022 will only replace 7.0 percent of the nation's expected gross annual gasoline consumption [6]. However, continued support for the biofuels program through government incentives such as feedstock incentives is expected to influence expansion of energy feedstock production in the USA. Such expansion could lead to biomass crop production on marginal lands, which are typically lands that are prone to high erosion, thereby diminishing soil productivity of lands that are enrolled in some form of conservation [7]. In the USA, 
land is enrolled in conservation programs through Conservation Reserve Program (CRP). Under the CRP, farmers agree to temporarily retire environmentally sensitive land from agricultural production; however, they allow grasses to grow that improve the lands health and quality [8]. It was estimated that the addition of CRP land to crop production would result in a decrease in crop prices due to increase in supply, consequently $\$ 5.0$ billion per year increase in consumer surplus; however, such gains are accompanied by an expense of 145 million tons in increased annual soil erosion [9]. Similarly, it was estimated that expansion of corn ethanol production would increase nitrogen losses from corn fields by 20 percent [10]. To mitigate such nutrient and sediment loadings, substantial management costs would be incurred [11]. Such research suggests that production of feedstock for biofuels on these lands could potentially negate the environmental benefits achieved from the CRP program.

This paper focuses on evaluation of the implications of dedicated biomass crop as feedstock for bioenergy production, alternative energy policies, and government initiatives on agricultural producers and consumers. The specific objectives of this study include application of a national quantitative model, Agricultural Simulation Model (AGSIM) [12], to estimate the impacts of biomass crop production intended to meet the cellulosic component of the biofuel mandate in addition to the grain-based biofuel mandate. The economic impacts estimated include effects on cropping patterns, commodity prices, fertilizer use, fertilizer prices, consumer and producer surplus, and trade balance. The base estimation is followed by sensitivity analyses based on alternative assumptions related to expiring CRP grassland acres returning to crop production and higher per acre yield of biofuel feedstock. Some recent studies have provided impacts on grain crop prices as a result of biofuel policies [13].

To produce sufficient biomass to meet the biofuel mandate, it is reasonable to assume competition for cropland between biomass crops and traditional crops, which can affect food and feed prices $[9,14,15]$. The current analyses improve on the existing literature $[13,16]$ on evaluation of biofuel mandates by accounting competition for land with feed grain or other commodity crop productions across United States, that is, analyzing the impacts at a national scale rather than at regional scale. The analysis accounts for supply and demand dynamics, including export demand relationship of all major row crops in the USA. Additionally, in estimating the overall economic impacts we allowed for fertilizer price adjustments. Such a framework is an improvement to studies that analyzed economic effects of biofuel policies accounting for only the corn markets [17]. Interesting relationships could evolve such that the response in commodity prices may improve the economic position of agriculture but harm consumers and the balance of trade. Clearly, if the USA is to achieve some balance between food, fiber, timber, energy, and the resources needed for a sustainable agriculture, there is a need for a balanced evaluation of alternative biofuel policies.

\section{Materials and Methods}

2.1. Model Description: AGSIM. AGSIM is an econometricsimulation model. It is based on a large set of statistically estimated demand and supply equations for major field crops and livestock feed, regionalized for the nine US Department of Agriculture (USDA) production regions [12]. AGSIM was initially developed in 1977 to evaluate the economic impacts of using corn, grain sorghum, small grains, and crop residues to convert to ethanol. The model has undergone subsequent revisions. It was used to evaluate several agricultural policies such as expansion of CRP acreage, tax on nitrogen fertilizer in the USA, and CRP land returning to production. Application of the model provides insight into expected impacts of alternative policies relative to shifts in cropping patterns, crop prices, fertilizer use, fertilizer prices, consumer and producer surplus, and trade balance $[3,18]$.

The current version of AGSIM includes supply and utilization of major crops. The demand for each commodity is separated into imports, exports, livestock feed, food, fiber, ethanol production, other domestic uses, ending stocks, and residual use stocks, all keyed to the USDA annual baseline, as typically required by USDA and USEPA for their internal policy discussions. The USDA baseline is an annual report that provides long-run projections for the US agricultural sector and provides a basis of comparison assessing expected impacts of alternative policies and technologies [19].

For this study, exogenously specified biofuel policies are incorporated relating to cropland needed for biomass production to meet the RFS for cellulosic ethanol. The model provides an estimate of a set of prices for all commodities that simultaneously clear all markets in each year, affecting profitability and cropping patterns in subsequent years. The model also provides estimates of economic surplus, calculated as the change in price times the quantity for consumers and change in net farm income for producers. AGSIM, as applied in this study, is designed to provide estimates up to year 2031.

AGSIM is different from other large-scale agricultural economy models in two ways. First, AGSIM uses a single equation to account for total planted acreage in a region, while a set of share equations allocate the total acreage to individual crops in that region. Second, acreage response is based on expected net returns per acre of crop alternatives rather than unit price, thus allowing for evaluation of policies that could change production costs and yields.

2.2. Methodology. The current analysis is based on the following assumptions: (1) cellulosic-based fuels come from a dedicated-biomass crop, switchgrass (SG), (2) production will take place on US cropland primarily planted to traditional crops, and (3) no CRP land returns to crop production; that is, such land remains in pasture or other conserving use. Switchgrass is used across all US regions in the analyses as the biofuel feedstock. It is recognized as a model species for ethanol production by the US Department of Energy due to its high-yielding potential, tolerance to water and nutrient deficits, and noninvasive nature and can be grown on marginal lands $[20,21]$. Sensitivity analyses are conducted 
TABLE 1: Description of the biofuel production scenarios under the base case where no conservation reserve program land returns to crop production.

\begin{tabular}{ll}
\hline Scenario $^{\mathrm{a}}$ & Explanation \\
\hline $0+16$ & Zero billion gallons of grain ethanol and sixteen billion gallons of biomass ethanol \\
$16+16$ & Sixteen billion gallons each of grain ethanol and biomass ethanol \\
$0+20$ & Zero billion gallons of grain ethanol and twenty billion gallons of biomass ethanol \\
$16+20$ & Sixteen billion gallons of grain ethanol and twenty billion gallons of biomass ethanol \\
\hline
\end{tabular}

${ }^{a}$ The scenarios are slightly different from the Renewable Fuel Standard (RFS) mandate. The RFS mandate requires production of 36 billion gallons of renewable fuels by 2022, with 15 billion gallons of grain ethanol, 20 billion gallons of biomass ethanol, and one billion gallons of biodiesel. Due to lack of reliable estimates in the literature on biomass to biodiesel conversion, it was reasonable to assume that the additional one billion gallons of ethanol in the RFS mandate is supplied through corn ethanol.

where the CRP restriction is released; that is, marginal lands previously in conservation use but currently not under a contract are allowed to return to crop production. In addition, the analyses also estimate the economic implications of potentially higher per acre yield of biomass crop. The basic underlying parameter is that the RFS mandate will be met starting with 250 million gallons in 2011 and reaching 16 billion gallons production by 2022 [6]; however, it is recognized that the RFS for biomass-based fuels is being reduced based on updated market assessments. Four production scenarios are developed for evaluation, each with alternative levels of biofuels mandates initially assumed. Brief descriptions of the scenarios are presented in Table 1.

Utilization of a uniform yield level to identify the number of biomass acres for each of the US farm resource regions might either overestimate or underestimate the economic impacts of biomass crop production. Due to lack of data on SG yields for the US farm resource regions specified in AGSIM, hay yield for each region is used as a proxy to define relative SG yields. The uniform harvested SG yield per acre is adjusted based on relative differences in the hay yields for each of the nine US farm resource regions. Using hay crop yield allows accounting for the heterogeneity in crop yields across regions.

The biomass acres are estimated as follows. First, total number of biomass acres required to meet the RFS mandate is estimated using a uniform yield of 2.69 tons per acre and an ethanol conversion rate of 96.5 gallons per ton of biomass. The ethanol conversion rate is the average of the switchgrass to ethanol conversion estimates reported in the literature. The literature used to derive the ethanol conversion estimate can be found in [22]. Next, the percentage relationship of regional cropland to the total US cropland over the nine US farm resource regions is used as a criterion to allocate the required biomass acres across regions. The region's share in total cropland criterion provides the percentage of biomass acreage for each region and that region's share of production of annual cellulosic ethanol mandate. Finally, the acres across regions are then adjusted based on relative SG yields estimated using the regional hay yields. Since the base case analysis assumes no return of expired CRP land to crop production, the acres needed for biomass crop production are obtained by replacing the traditional crop acres. The remainder of the land in each region adjusts across crops based on their relative net profitability. Such acreage shifts affect supplies of traditional crops and consequently their prices.

Fertilizer use and price effects of biomass production are also an output of AGSIM. However, AGSIM does not allow incorporating the fertilizer demand relative to the expected yield level of the biomass crops on a regional basis. Hence, fertilizer requirements corresponding to a yield level of $3.0^{1}$ tons per acre are used, an average of adjusted SG yields across all nine US farm resource regions. Nitrogen $(\mathrm{N})$, phosphorous $(\mathrm{P})$, and potassium $(\mathrm{K})$ fertilizers are used in $3: 1: 2$ proportions, resulting in $60 \mathrm{lb} \mathrm{N}, 20 \mathrm{lb} \mathrm{P}$, and $40 \mathrm{lb} \mathrm{K}$ being applied per acre for SG production in each region. Due to the unavailability of national data on SG yields, prices, and other costs, the present version of AGSIM does not account for the net farm income associated with SG production. Hence, the producer surplus estimates only represent the net income associated with major crops.

\section{Results and Discussion}

The aggregate economic effects of production of the biofuels scenarios are measured relative to a zero-production level of biofuels (Baseline). Included in the implications are changes in cropping patterns of major crops, effects on commodity prices, impact on fertilizer prices, trade balance, and consumer and producer surplus. The results presented herein are for year 2022 after meeting the RFS mandates.

3.1. Cropping Pattern Implications. Implementation of biomass crop production as a feedstock for energy influenced the cropping pattern in all nine of the US farm resource regions. Table 2 is a presentation of the estimates that indicate the average changes in major crop acres, with negative numbers indicating a decrease in crop acres. Due to the "no-CRP acres availability" assumption, the resulting required biomass acres in each region originate from traditional crop production acres. The remainder of the land adjusts across crops based on their relative net profitability.

Corn acres decreased the most under the cellulosic-only ethanol mandate (i.e., $0+16 ; 0+20$ ) but their decrease was relatively smaller under the grain and cellulosic ethanol mandate scenarios (i.e., $16+16 ; 16+20$ ) (Table 2). Soybean acres decreased relatively higher under all biofuel scenarios ${ }^{2}$. 
TABLE 2: Average change in major crop acres from baseline due to biofuel production mandate across the US farm resource regions under specified biofuel scenarios and no conservation reserve program assumption (million acres).

\begin{tabular}{lcccccc}
\hline Scenario $^{\mathrm{a}}$ & Switchgrass & Corn & Soybean & Wheat & Cotton & Hay \\
\hline Baseline & 0.0 & 82.6 & 79.5 & 52.6 & 11.6 & 59.6 \\
\hline & & Change in major & crop acres relative to baseline, million acres \\
$0+16^{\mathrm{b}}$ & 61.7 & -11.8 & -17.2 & -10.0 & -1.5 & -5.3 \\
$16+16$ & 61.7 & -4.7 & -16.3 & -11.2 & -1.5 & -5.6 \\
$0+20$ & 77.1 & -14.7 & -21.1 & -12.0 & -1.8 \\
$16+20$ & 77.1 & -6.4 & -19.9 & -13.6 & -1.8 & -6.9 \\
\hline
\end{tabular}

${ }^{\mathrm{a}}$ Refer to Table 1 for description of biofuel scenarios.

${ }^{\mathrm{b}}$ The total decrease in major crop acres is 45.8 million acres. The remaining 15.9 million acres $(61.7-45.8=15.9)$ for SG production to fulfill the cellulosic ethanol mandate is available from acreage adjustments among other crops (barley, oats, cotton, peanuts, and rice) included in the AGSIM model. It is the same case with other scenarios.

Such shifts in crop acres are expected to influence the supplies of crops and consequently their prices.

\subsection{Impacts on Crop and Fertilizer Prices. As farmers respond} to the biofuel mandates, crop production levels and prices adjust. The shifts in traditional crop acres to SG production are projected to result in a reduction in supplies of the major crops and an eventual increase in prices for all crops (Table 3). Although corn and soybean account for more than 90 percent of the ethanol and biodiesel production in USA, the effects of the RFS mandate are reflected in acres and consequently in the prices of all crops. Crop prices increased across all scenarios. Corn and wheat price increased the most, by approximately 50 percent. Such price increases can affect the quantity supplied (i.e., price elasticity of supply); but the biofuel obligation along with no acres available from CRP forces a balance across available land.

Biomass crops such as SG are described as having relatively low-input requirements on a per acre basis [23], compared to crops such as corn. Biomass production resulted in cropping pattern shifts such that there are fewer acres in input-intensive crops, causing a decrease in total use of primary plant nutrients and, in turn, a decrease in fertilizer prices (Table 3). Sensitivity analyses with yield levels for SG of 5.0 and 7.0 tons per acre provide additional insights relative to the fertilizer implications for the combined effects of higher yield levels of SG and effects of biofuel production mandates. Availability of additional land for crop production by relaxing the assumption of expired CRP land potentially returning to crop production is also examined below.

3.3. Welfare Implications. The estimated aggregate economic effects of producing cellulosic feedstock for energy are presented in Table 4 . The effects indicate a loss in economic well-being in the food sector due to high commodity prices. For example, RFS mandate production of 36 billion gallons resulted in an increase in net farm income by $\$ 49.7$ billion due to higher crop prices. This increase is more than offset by a loss in consumer surplus of $\$ 55.9$ billion (from crop price increases). Similarly, the US trade balance, a measure of net exports, decreased compared to the baseline. The production of a cellulosic mandate in the AGSIM model occurs by displacing major crop acres across all US farm resource regions. Economic adjustments for all the major crops, especially on the supply side of the market, have been accounted. Due to biofuel production mandates, supplies of major crops decreased due to increased domestic demand, consequently reducing net exports.

These results illustrate the impact of a government mandate for production of biofuels on producers and consumers. It is these types of unanticipated consequences that policy makers need to consider before enacting policies to address one issue, such as energy. Furthermore, the 36 billion gallons of ethanol is not a net addition to the fuel supply. Accounting for the fossil fuels for production and conversion of the ethanol, the net addition to the fuel supply from production of 36 billion gallons of ethanol is approximately 7.5 billion gallons [24]. Our results are different from studies that have analyzed similar policies. In our analysis, using AGSIM, both demand and supply dynamics have been incorporated including the corn export demand relationship. Fertilizer price adjustments within the domestic market are accounted in total surplus estimations. Any or all of these differences in the analysis framework can lead to different results in comparison with studies that evaluated national biofuel policies [17].

3.4. Sensitivity Analyses. Due to numerous unknowns related to biofuels, including the potential of converting CRP lands to crop production and conflicting information on SG yields, an expanded set of AGSIM applications (i.e., sensitivity analyses) are conducted across a wide array of assumptions. The results from these sensitivity analyses provide added insights as to the potential economic impacts of biofuel production.

\subsubsection{Sensitivity Analyses: Conservation Reserve Program} Acres. The potential return of CRP acres to cropland assumes no additional costs to convert CRP land to cropland. Data regarding expiring CRP contracts currently under grassland and trees by region and by year are available from the Farm Service Agency. There are 28 million acres of grasslands in CRP that could potentially return to crop production. A series of sensitivity analyses includes allowing first 25 , then 50 , and finally 100 percent of the expiring grassland CRP 
TABLE 3: Average percentage change in major crop and fertilizer prices from baseline due to biofuel production mandate across the US farm resource regions under specified biofuel scenarios and no conservation reserve program acres availability assumption.

\begin{tabular}{|c|c|c|c|c|c|c|c|c|}
\hline Scenario $^{\mathrm{a}}$ & Corn & Soybean & Wheat & Cotton & Hay & $\mathrm{N}$ & $\mathrm{P}$ & $\mathrm{K}$ \\
\hline & \multicolumn{5}{|c|}{ Crop prices } & \multicolumn{3}{|c|}{ Fertilizer prices; $\$ /$ ton } \\
\hline Baseline $^{\mathrm{b}}$ & $\$ 3.3 / \mathrm{bu}$ & $\$ 9.7 / \mathrm{bu}$ & $\$ 5.3 / \mathrm{bu}$ & $\$ 0.7 / \mathrm{lb}$ & $\$ 115.1 /$ ton & $\$ 333.1$ & $\$ 308.2$ & $\$ 309.1$ \\
\hline & \multicolumn{5}{|c|}{ Percent change from baseline } & \multicolumn{3}{|c|}{ Percent change from baseline } \\
\hline $0+16$ & $21.3 \%$ & $11.8 \%$ & $30.3 \%$ & $20.8 \%$ & $17.9 \%$ & $-9.3 \%$ & $-10.6 \%$ & $-7.4 \%$ \\
\hline $16+16$ & $41.2 \%$ & $22.7 \%$ & $39.3 \%$ & $20.6 \%$ & $19.2 \%$ & $-5.0 \%$ & $-6.7 \%$ & $-4.1 \%$ \\
\hline $0+20$ & $27.9 \%$ & $15.7 \%$ & $39.6 \%$ & $27.7 \%$ & $22.7 \%$ & $-11.1 \%$ & $-12.7 \%$ & $-8.7 \%$ \\
\hline $16+20$ & $51.9 \%$ & $28.3 \%$ & $50.0 \%$ & $27.2 \%$ & $24.0 \%$ & $-6.7 \%$ & $-8.6 \%$ & $-5.3 \%$ \\
\hline
\end{tabular}

${ }^{\mathrm{a}}$ Refer to Table 1 for description of biofuel scenarios.

${ }^{\mathrm{b}}$ Baseline refers to no biofuel production.

TABLE 4: Average annual change in economic factors from the baseline levels due to biofuel production mandate under specified biofuel scenarios and no conservation reserve program acres availability assumption (billion dollars).

\begin{tabular}{lccccc}
\hline Scenario $^{\mathrm{a}}$ & Net farm income $(A)$ & Consumer surplus $(B)$ & Biofuel subsidy $^{\mathrm{b}}(C)$ & Total surplus $(A+B-C)^{\text {Trade balance }}$ \\
\hline Baseline $^{\mathrm{c}}$ & $\$ 65.4$ & $\$ 158.9$ & $\$ 0.0$ & $\$ 224.3$ & $\$ 49.2$ \\
\hline & & Change in welfare impacts relative to baseline, billion dollars per year & \\
$0+16$ & 15.7 & -7.5 & 0.0 & 8.2 & 0.3 \\
$16+16$ & 43.1 & -42.8 & 0.0 & 2.4 & -2.3 \\
$0+20$ & 19.9 & -17.5 & 0.0 & -6.2 & -2.7 \\
$16+20$ & 49.7 & -55.9 & 0.0 & -5.9 \\
\hline
\end{tabular}

${ }^{\mathrm{a}}$ Refer to Table 1 for description of biofuel scenarios.

${ }^{\mathrm{b}}$ Assuming subsidy for only cellulosic-based ethanol.

${ }^{\mathrm{c}}$ Baseline refers to no biofuel production.

acreage (i.e., 7, 14, and 28 million acres) to return to biomass and/or crop production by region and by year. Crop acreage shifts are variable for the alternative CRP acres returning to production. The resulting impacts are presented in Table 5. The associated relative changes in economic impacts are compared to the solution of $16+16$, no-CRP acres availability scenario. This analysis assumes the same productivity as nonCRP land.

Within the operation of AGSIM, there are many economic principles, including the response of price to a change in supply, typically referred to as price elasticity of supply. A relatively smaller percentage decrease in crop prices due to addition of CRP acres to cropland (Table 5) suggests a relatively inelastic supply. Such an effect indicates change in demand rather than supply is a major factor affecting crop prices. For example, corn price that increased by 41.2 percent (Table 3) for the $16+16$ scenario (effect of demand) in the benchmark analyses decreased by only 12.8 percent (Table 5 ) for the scenario of addition of 28 million acres of CRP land to crop production (effect of supply). Much the same as crop price changes, fertilizer prices doubled when CRP acres doubled from 14.0 to 28.0 million acres.

With more land, conventional wisdom suggests that farmers would be better off financially. However, due to price elasticity of demand, the lower commodity prices more than offset the increase in acres, resulting in a lower net income compared to biomass production under the "no-CRP acres availability" assumption. However, the loss in net income is offset partially by a higher consumer surplus due to lower commodity prices. The total economic surplus due to the addition of 28 million CRP acres increased by 3.2 percent. The availability of additional land from CRP toward crop production resulted in more land available to increase production acres of traditional crops; consequently, domestic supplies of these crops increase. With supplies exceeding domestic demand, net exports increase. The net exports that were initially negative have subsequently become positive because of increased domestic supply. These economic impacts are suggestive that competition from biomass production for available land is partially offset by the CRP grassland returning to crop production. Not included in this analysis are the potential environmental impacts of converting marginal and erosion prone land to crops. Such phenomena represent externalities not quantified herein. Estimation of the costs of mitigation of water quality impacts of energy crop production showed substantial costs to internalize the water pollution externality [11].

3.4.2. Sensitivity Analyses: Switchgrass Yields. Efforts toward developing high-yielding biomass varieties could improve the yield potential, resulting in fewer biomass acres being required to meet the cellulosic biofuel mandate. Such a decrease in biomass acres would reduce competition for land with traditional crops, thereby influencing crop prices, fertilizer prices, and consequently welfare measures. Hence, biomass acreage requirements are reestimated using SG yields 


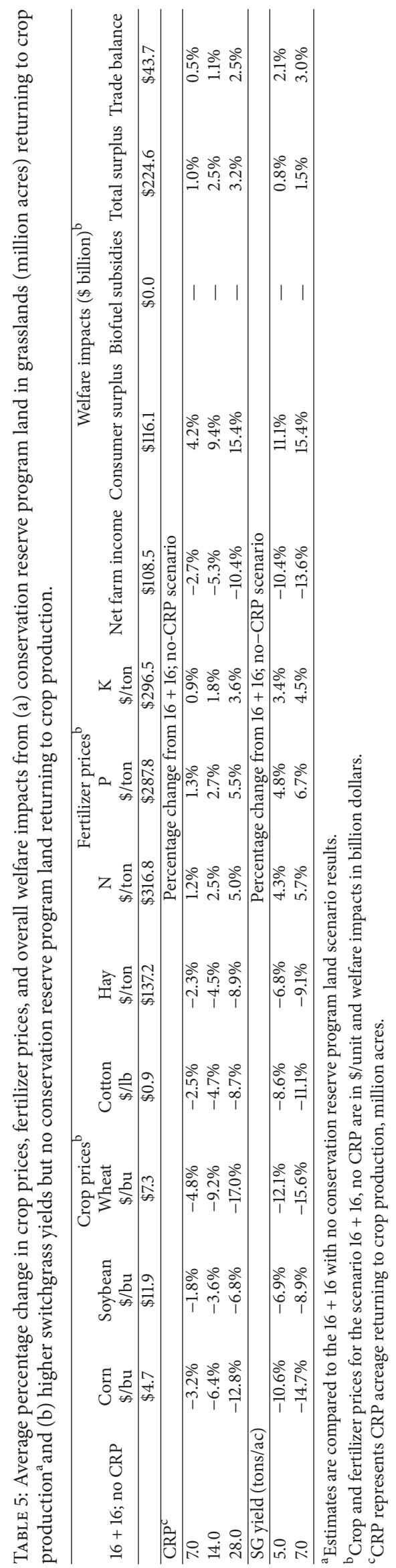


of 5.0 and 7.0 dry tons per acre. Researchers from Oakridge National Laboratories and Dartmouth College compiled observations on SG yields across 17 states and reported average yields of 5.0 to 7.0 tons per acre for lowland and upland ecotypes, respectively [25]. The uniform per acre yields of SG are adjusted by region based on relative differences in regional hay yields to account for the heterogeneity in crop yields across US farm resource regions. The results from the SG yields sensitivity analyses are particularly important for justification against any implication that relatively low yields are assumed for the analysis. The impacts of higher SG yields can be interpreted similar to the availability of additional land from relaxation of the no-CRP acres availability assumption. Table 5 includes the results of SG yields sensitivity analyses, which are compared to the solution of " $16+16$, no-CRP acres availability" scenario.

AGSIM allocates total cropland based on crops' relative net profitability. The availability of high-yielding biomass crops is evaluated as an increase (shift) in supply of land. With biofuel demand held constant, the additional acreage available due to increases in SG yields and consequent decreases in cropland required for biomass production shifts the supply curves of the crops to the right, resulting in decreases in crop prices. The results indicate a trend of decreasing crop prices across all major crops due to increases in supplies. Fertilizer prices increase under higher biomass yield scenarios. Increases in crop acreages of traditional crops that are relatively fertilizer intensive compared to biomass crops result in fertilizer demand increases and eventually higher fertilizer prices.

Welfare effects indicate that farm income decreased due to lower crop prices. Due to the price elasticity of demand, decreases in crop prices offset the increase in supplies, resulting in lower net income. However, decreases in crop prices produced a slight increase in consumer surplus. These results are potentially useful to the public's understanding of the economic consequences associated with a bioenergy policy even with potential of added cropland and greater per acre biomass yields.

\section{Conclusion}

Possible domestic and international economic impacts potentially resulting from the US cellulosic biofuel mandates reflected in the RFS are estimated. A dedicated cellulosic feedstock, switchgrass, is considered as a feedstock. Economic implications of additional land currently in conservation use returning to crop production and reducing competition for existing cropland are analyzed.

Substantial increases in crop prices because of the biofuel mandate were observed across all scenarios, whereas prices of major plant nutrients decreased. Higher commodity prices resulted in loss in consumer surplus. The aggregate economic effects indicate a negative total economic surplus. The trade balance, a measure of net exports, decreased due to reduced supplies and increased domestic demand of major crops from the biofuel sector. The current analyses of evaluation of firstand-second-generation biofuels produced results analogous to [3], that is, increases in crop and fertilizer prices and a decrease in total economic surplus. The results indicate that the present biofuel policies are associated with large costs to consumers in terms of increased commodity prices. These price increases can be expected to affect lower income society more severely. Thus, there is a need to identify and consider those sectors most impacted by energy and other policy decisions. Alternatively, the beneficiaries are the agricultural producers whose net income is projected to increase. Sensitivity analyses assuming CRP grassland acres returning to crop production and higher biomass yields produced similar impacts. In addition, there are potential environmental impacts of production of dedicated biomass crops on marginal lands, which are not incorporated into the total surplus estimation.

While the production of biomass for ethanol is pushed as a future energy solution, there are unexpected consequences of bioenergy policy that are often ignored. The results presented in this paper represent a robust set of expected shifts and economic impacts. The results suggest a need for policy makers to be informed and warrant identifying and considering multiple alternative energy sources to achieve a sustainable energy goal. Reductions in consumer surplus evolve due to price increases for commodities.

The results of this study are obviously influenced by a number of factors and assumptions, but they also provide significant insights into the impact of cellulosic biofuels on the economy. Some of the limitations of this study are important to consider in future research to improve the analyses. The limitations include the following:

(i) It is assumed that a dedicated cellulosic crop competes directly with existing cropland, while there are other sources of cellulosic feedstocks such as timber and hay that could be considered.

(ii) The data on biomass crops relative to conversion to fuel are premature. A consistent, science-based estimate on specific biomass types conversion coefficients would be useful in providing better estimates of the aggregate welfare impacts.

(iii) The model does not capture the effect of future developments or technology change in the USA and in the rest of the world that could affect the US food sector.

(iv) Net farm income associated with the biomass production is not accounted for in the economic impacts estimation, mainly due to unavailability of data on national SG yields, prices, and costs. Availability of such data would help to identify better estimates of total economic surplus.

(v) Economic costs of mitigation of externalities water quality deterioration, soil erosion, and greenhouse gas emissions because of production on marginal lands are not included.

(vi) The value of having mobile fuels may override many of the impacts described in this study. The issues of form and place are not considered. However, it is 
important to consider the potential of an alternative fuel not only from an energy perspective, but also from an economic perspective. Often times, however, economic approaches are distorted by government intervention through subsidies, tariffs, and so forth. Potential benefits of an increase in mobile fuels with a lower per gallon price were not included in the analysis but are deemed worthy of being included in future research.

\section{Disclosure}

Views, opinions, and results presented in the paper are of the authors and do not necessarily represent those held by the authors' current or past employers.

\section{Conflict of Interests}

The authors declare that there is no conflict of interests regarding the publication of this paper.

\section{Acknowledgment}

Work on this paper was completed while the corresponding author was housed in the Department of Agricultural Economics at Texas A\&M University.

\section{Endnotes}

1. Although 3.0 dry tons per acre yield is considered possible for SG, only an average yield of 2.69 dry tons per acre is realized due to varied planting and harvesting dates, to minimize costs of production.

2. Table 2 presents only major crop acreage adjustments due to SG production. It is important to note that the model also includes other crops-barley, oats, cotton, peanuts, and rice; and acreage is adjusted among those crops making up the difference in reduction in acres not shown in Table 2 .

\section{References}

[1] H. De Gorter and D. Drabik, "Policy update: the effect of biofuel policies on food grain commodity prices," Biofuels, vol. 3, no. 1, pp. 21-24, 2012.

[2] A. Elobeid, M. Carriquiry, J. Dumortier et al., "Biofuel expansion, fertilizer use, and GHG emissions: unintended consequences of mitigation policies," Economics Research International, vol. 2013, Article ID 708604, 12 pages, 2013.

[3] C. R. Taylor and R. D. Lacewell, "Aggregate economic effects of corn ethanol and soy-based biodiesel production," BioEnergy Policy Brief BPB-70209, 2009.

[4] S. L. Baier, M. Clements, C. W. Griffiths, and J. E. Ihrig, "Biofuels impact on crop and food prices: using an interactive spreadsheet," FRB International Finance Discussion Paper 967, 2009.
[5] US Environmental Protection Agency, "Renewable fuel standard program: standards for 2014, 2015, and 2016, and biomassbased diesel volume for 2017," Federal Register, vol. 80, no. 111, pp. 33100-33153, 2015.

[6] US Environmental Protection Agency, "Regulation of fuels and fuel additives: changes to renewable fuel standard program," Federal Register, vol. 75, no. 58, pp. 14669-15320, 2010.

[7] D. Pimentel, "Limits of biomass utilization," in Encyclopedia of Physical Science and Technology, vol. 2, Academic Press, New York, NY, USA, 2002.

[8] M. Stubbs, Conservation Reserve Program (CRP): Status and Issues, Congressional Research Service, Washington, DC, USA, 2014.

[9] C. R. Taylor and R. D. Lacewell, "Effects of corn ethanol and soy-based biodiesel production on soil erosion and return of conservation reserve program land to crop production," BioEnergy Policy Brief BPB-70409, 2009.

[10] E. Affuso and L. M. Duzy, "The Impact of US Biofuels Policy on Agricultural Production and Nitrogen Loads in Alabama," Economics Research International, vol. 2013, Article ID 521254, 16 pages, 2013.

[11] N. Adusumilli, T. Lee, M. Rister, and R. Lacewell, "The economics of mitigation of water pollution externalities from biomass production for energy," Resources, vol. 3, no. 4, pp. 721733, 2014

[12] C. R. Taylor and M. M. Taylor, Brief Description of Agsim: an Econometric-Simulation Model of the Agricultural Economy Used for Biofuel Evaluation, BioEnergy Policy Brief, 2009.

[13] H. D. Gorter, D. Drabik, and D. R. Just, "Biofuel policies and food grain commodity prices 2006-2012: all boom and no bust?" AgBioForum, vol. 16, no. 1, pp. 1-13, 2013.

[14] N. Adusumilli and A. Leidner, "The U.S. biofuel policy: review of economic and environmental implications," American Journal of Environmental Protection, vol. 2, no. 4, pp. 64-70, 2014.

[15] L. Marshall and Z. Sugg, Fields of Fuel: Market and Environmental Implications of Switching to Grass for U.S. Transport, World Resources Institute (WRI), Washington, DC, USA, 2010.

[16] B. C. English, T.-H. E. Yu, J. A. Larson, R. J. Menard, and Y. Gao, "Economic impacts of using switchgrass as a feedstock for ethanol production: a case study located in East Tennessee," Economics Research International, vol. 2013, Article ID 138485, 14 pages, 2013.

[17] H. de Gorter and D. R. Just, "The welfare economics of a biofuel tax credit and the interaction effects with price contingent farm subsidies," American Journal of Agricultural Economics, vol. 91, no. 2, pp. 477-488, 2009.

[18] C. R. Taylor, "AGSIM: an econometric-simulation model of regional crop and national livestock production in the United States," in Agricultural Sector Models for the United States: Descriptions and Selected Policy Applications, C. R. Taylor, K. H. Reichelderfer, and S. R. Johnson, Eds., Wiley-Blackwell, Hoboken, NJ, USA, 1991.

[19] P. Westcott, "USDA Agricultural Projections to 2020," OCE-111, 2011.

[20] S. McLaughlin, R. Samson, D. Bransby, and A. Wiselogel, "Evaluating physical, chemical, and energetic properties of perennial grasses as biofuels," in Proceedings of the 9th European Bioenergy Conference, pp. 1-8, Copenhagen, Denmark, June 1996.

[21] L. Wright, "Historical perspective on how and why switchgrass was selected as a "model" high-potential energy crop," Tech. Rep. ORNL/TM-2007/10, 2007. 
[22] N. C. Adusumilli, Economic Policy and Resource Implications of Biofuel Feedstock Production, Texas A\&M University, 2012.

[23] D. Tilman, J. Hill, and C. Lehman, "Carbon-negative biofuels from low-input high-diversity grassland biomass," Science, vol. 314, no. 5805, pp. 1598-1600, 2006.

[24] C. R. Taylor, R. D. Lacewell, and E. Seawright, Economic Cost of Biodiesel and Corn Ethanol per Net BTU of Energy Produced, BioEnergy Policy Brief, Texas A\&M AgriLife Extension Service, College Station, Tex, USA, 2010.

[25] S. D. Wullschleger, E. B. Davis, M. E. Borsuk, C. A. Gunderson, and L. R. Lynd, "Biomass production in switchgrass across the United States: database description and determinants of yield," Agronomy Journal, vol. 102, no. 4, pp. 1158-1168, 2010. 


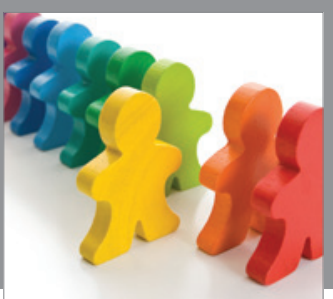

Autism

Research and Treatment
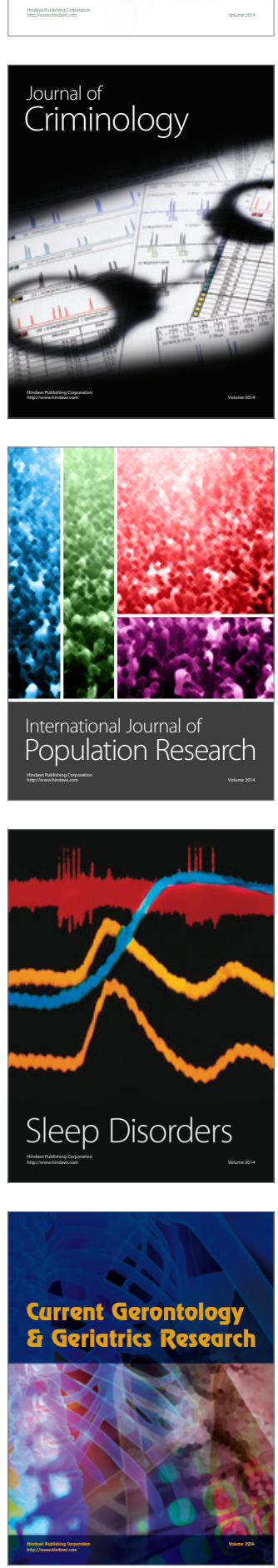

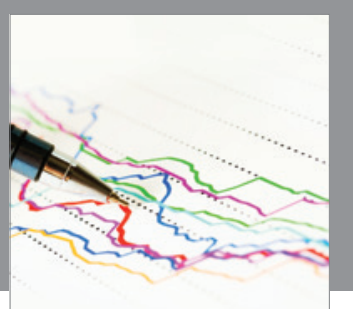

Economics

Research International
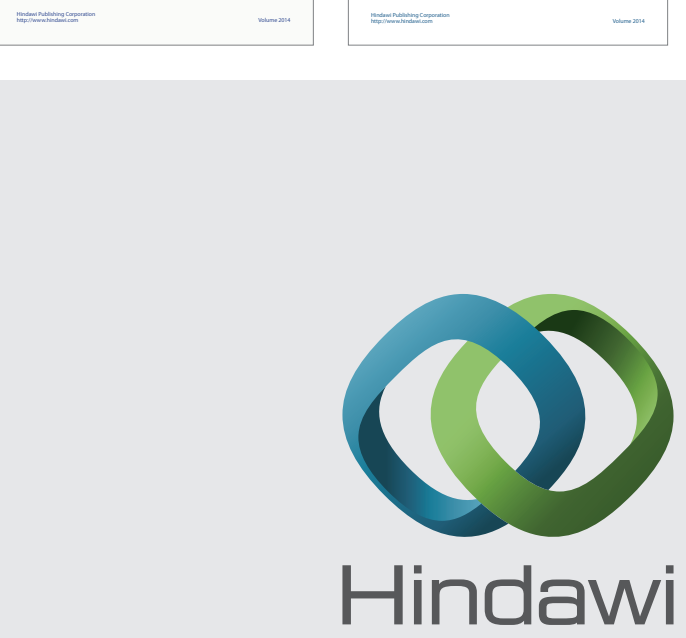

Submit your manuscripts at

http://www.hindawi.com
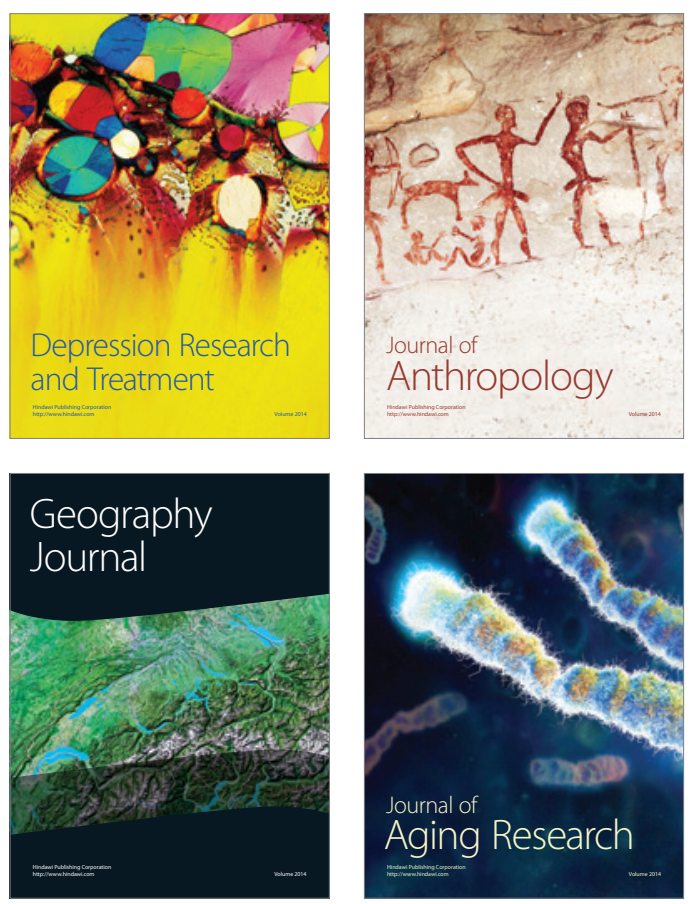
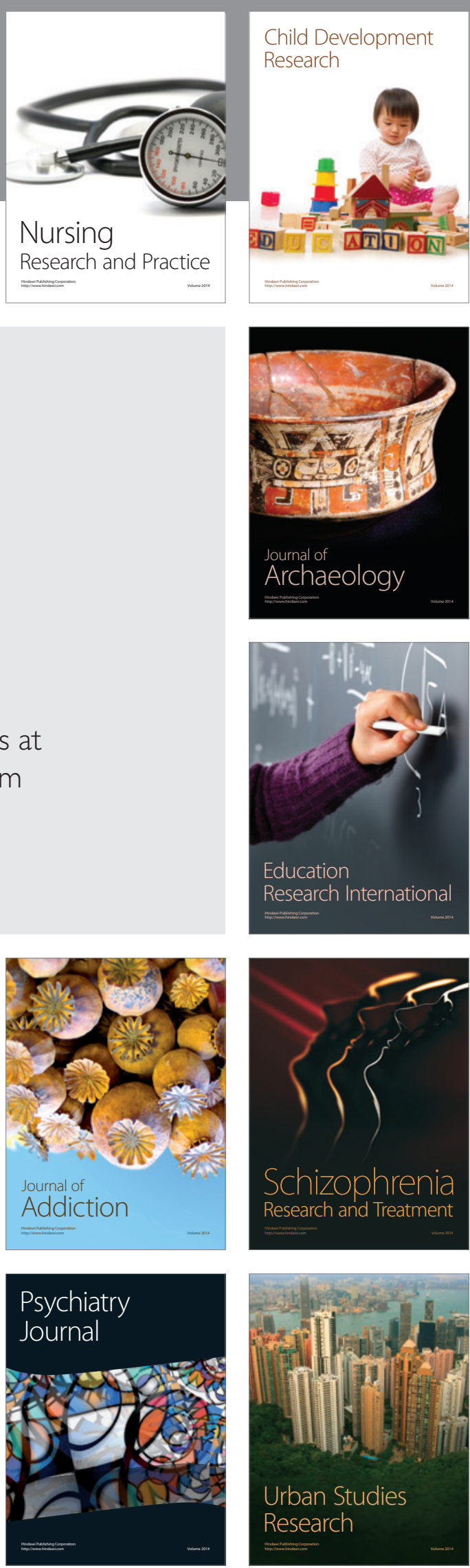